East African Medical Journal Vol. 85 No. 4 April 2009

MULTIFOETAL PREGNANCIES AT A MATERNITY HOSPITAL IN NAIROBI

F. Musili, MBChB, MMed, Specialist Obstetrician and Gynaecologist, Pumwani Maternity Hospital, P. O. Box 4284900100, Nairobi, Kenya and J.G. Karanja, MBChB, MMed, Associate Professor, Department of Obstetrics and Gynaecology, College of Health Sciences, University of Nairobi, P. O. Box 19676-00202, Nairobi, Kenya

Request for reprints to: Dr. F. Musili, P. O. Box 19836-00202, Nairobi, Kenya

\title{
MULTIFOETAL PREGNANCIES AT A MATERNITY HOSPITAL IN NAIROBI
}

\author{
F. MUSILI and J.G. KARANJA
}

\begin{abstract}
Objective: To review some of the aspects of multiple pregnancies.

Design: A retrospective review of multiple pregnancy deliveries.

Setting: Pumwani Maternity Hospital- Nairobi Kenya, between $1^{\text {st }}$ January and $31^{\text {st }}$ December 2006.

Subjects: Three hundred and twenty eight mothers with twins and two sets of triplet deliveries.

Results: The total annual deliveries were 15,642 . The twinning rate was one in 48 deliveries and the triplet rate was one in 7,821 deliveries. Most of the mothers were of low parity and in the lower age group. Majority had no previous history of twins and were married. The sex differences in both the first and second twins were as of the normal population with males being delivered more than females. Most of the twins were delivered alive through spontaneous vertex delivery (SVD). Majority of first twins had no complications while in second twins the majority had more complications. Most of the deliveries had no obvious congenital malformations. Most of the twins were of low birth weight and were of the same sex (monozygotic). The most common complications in both first and second twins were prematurity and asphyxia. The majority of the twins were diagnosed during the prenatal period and the most common method of diagnosis was by ultrasonography. The majority of the mothers had no complications. The most common maternal complications being preeclampia (PET) and anaemia.

Conclusion: Most of the mothers with multiple pregnancies were of low parity and in the lower age group. Diagnosis was mainly done by ultrasonography therefore emphasis should be done to improveclinical diagnosis especially in resource constrained facilities. A more detailed study should be undertaken especially the events in the pre-pregnancy and during the antenatal period. The present study assumes that same sex twins are the same as monozygotic twins. A more detailed study on the types of placentation would be useful. As PET, anaemia, prematurity and asphyxia are the most common maternal and neonatal complications medical workers need to be made aware of the appropriate management of the conditions. These babies will need longterm follow-up
\end{abstract}

\section{INTRODUCTION}

A multifoetal birth is defined as more than one foetus being born of a pregnant woman. The prevalence since1970's has increased due to widespread use of assisted reproductive technologies to treat infertility especially in the developed world.

Multifoetal pregnancies are high risk pregnancies with a number of associated foetal and neonatal complications. There are two types of twins: monozygotic and dizygotic. In dizygotic twins two sperms fertilise two ova. These forms separate amnions, chorions and placenta. In monozygotic twins, a single fertilised ova splits during the first two weeks after conception. If twinning occurs beyond 12 days after fertilisation then the monozygotic pair only partially split, resulting in conjoined twins. Triplets can be monozygotic, dizygotic or trizygotic. Two consecutive zygotic splitting with one split results in a vanished foetus and monozygotic triplets $(1,2)$.

The frequency of monozygotic twins is constant worldwide that is approximately 4 per 1000 births in contrast to dizygotic twinning. Naturally occurring triplet births occur approximately in 1 per 7000-10000 births. Naturally occurring quadruplets births occur in 1 per 600,000 deliveries $(3,4)$.

The highest birth rate of dizygotic twins occurs in African and the lowest birth rate in dizygotic occurs in Asia. The Yorubas of Western Nigeria have a frequency of 45 twins per 1000 live births and 
approximately $90 \%$ are dizygotic. The Ibos in Nigeria have a frequency of 1 in 22 deliveries local studies on multifoetal deliveries are largely anecdotal $(5,6)$.

The foetal mortality rate for twins is four times the mortality rate for singleton births. Maternal age has no effect on monozygotic twin births. Advanced maternal age ( $>35$ years) is associated with increased risk of dizygotic twins. However the prevalence of naturally occurring twin births has increased recently because of the trends to delay childbearing to later years $(7,8)$. Most multiple pregnancies were diagnosed prenatally. These are mainly due to a history of increased signs and symptoms of pregnancy.

Maternal ultrasonography confirms most of the multiple pregnancies. Specific medical care depends on whatever complications are present. The usual mode of delivery of higher order multiple pregnancies is by Caesarean section.

The delivery room requires adequate personnel skilled in neonatal resuscitation. The prognosis of infants born from multiple gestations depends upon the complications that develop. Multiple births have significant economic implications to the family and the health care system.

Pumwanimaternity hospital(PMH) is the busiest obstetric unit in East and Central Africa handling over 20,000 deliveries annually. This study attempts to look at some aspects of multifoetal pregnancies.

\section{MATERIALS AND METHODS}

This was a retrospective study covering the period $1^{\text {st }}$ January 2006 to $31^{\text {st }}$ December 2006. It involved retrieving all the files of the multifoetal babies delivered during the study period.

Data analysis: Data were coded, entered and analysed using the normal statistical packages. Analysis of the results included comparisons between and within groups. Statistical analysis was performed by calculating frequency, means, standard deviations and chi square tests. Approval of the project was sought from the PMH ethical committee.

\section{RESULTS}

In 2006 there were 15,642 deliveries out of which 328 were twin deliveries and there were two sets of triplets. The age distribution is tabulated in Table 1. The majority of the women delivering $(84.8 \%)$ were below 30 years of age. The mean age was 25.9 years with a median age of 25 years. Most of the parturients were of low parity (Table 2). Those with between one and three pregnancies were $81.5 \%$. There was no monthly patterns in terms of the number of deliveries though the highest number of deliveries were between the months of March to July. There was no previoushistory of twins in $87.0 \%$ of the deliveries. Those who were married were $92.7 \%$ as compared to single women who comprised $7 \%$. In both the first and second twins there was a preponderance of more males being delivered than females. The two sets of triplets had equal sexes delivered. Majority of the deliveries were live births. Most of the mothers had spontaneous vaginal deliveries that is $64.8 \%$ and $63.6 \%$ for first and second twins. The second twins had more complications as compared to first twins (51.2\% as compared to $45.5 \%) 70.6 \%$ of the mothers had no complications as compared to $27.9 \%$ who had complications. Only two sets of twins had congenital malformations in which one involved the nervous and the other involved the skeletal system. In terms of sexes $61.2 \%$ of the twins were of the same sex. Therefore we can assume that the majority of the twins were monozygotic as compared to dizygotic. In the majority of the cases $(70.3 \%)$ the diagnosis was made in the prenatal period. Ultrasonography was the method of diagnosis in $58.8 \%$ as compared to $16.1 \%$ of the cases where diagnosis was made clinically.

Table 1

Maternal age distribution

\begin{tabular}{cccc}
\hline Age (years) & Frequency & $(\%)$ & Cumulative \\
\hline$>20$ & 41 & 12.4 & 12.4 \\
$21-25$ & 128 & 38.8 & 51.2 \\
$26-30$ & 111 & 33.6 & 84.8 \\
$31-35$ & 39 & 11.8 & 96.7 \\
$<35$ & 11 & 3.3 & 100 \\
\hline Total & 330 & 100 & \\
\hline
\end{tabular}

Table 2

Gravidity

\begin{tabular}{lccc}
\hline Gravidity & Frequency & $(\%)$ & Cumulative $(\%)$ \\
\hline 1 & 111 & 33.6 & 33.6 \\
2 & 94 & 28.5 & 62.1 \\
3 & 64 & 19.4 & 81.5 \\
4 & 34 & 10.3 & 91.8 \\
5 & 16 & 4.8 & 96.7 \\
6 & 5 & 1.5 & 98.2 \\
7 & 4 & 1.2 & 99.4 \\
8 & 1 & 0.3 & 99.7 \\
9 & 1 & 0.3 & 100 \\
\hline Total & 330 & 100 &
\end{tabular}


Table 3

Foetal weight-1st twin

\begin{tabular}{lccc}
\hline $\begin{array}{c}\text { Weight } \\
\text { (gms) }\end{array}$ & Frequency & $(\%)$ & Cumulative $(\%)$ \\
\hline$<500$ & 4 & 1.2 & 1.2 \\
$501-1000$ & 11 & 3.3 & 4.6 \\
$1001-1500$ & 34 & 10.3 & 14.9 \\
$1501-2000$ & 74 & 22.4 & 37.4 \\
$2001-2500$ & 99 & 30.0 & 67.5 \\
$2501-3000$ & 80 & 24.2 & 91.8 \\
$>3001$ & 27 & 8.2 & 100.0 \\
\hline Total & 329 & 99.7 & \\
\hline
\end{tabular}

Table 4

Foetal weight-2nd twin

\begin{tabular}{lccc}
\hline $\begin{array}{l}\text { Weight } \\
\text { (gms) }\end{array}$ & Frequency & $(\%)$ & Cumulative $(\%)$ \\
\hline$<500$ & 3 & 9 & 9 \\
$501-1000$ & 16 & 4.8 & 5.8 \\
$1001-1500$ & 33 & 10.0 & 15.8 \\
$1501-2000$ & 63 & 19.1 & 35.0 \\
$2001-2500$ & 124 & 37.6 & 72.6 \\
$2501-3000$ & 68 & 20.6 & 93.3 \\
$>3000$ & 22 & 6.7 & 100 \\
\hline Total & 329 & 99.7 & 11508 \\
\hline
\end{tabular}

Table 5

Foetal weight of the triplets

\begin{tabular}{lccc}
\hline $\begin{array}{l}\text { Weight } \\
\text { (gms) }\end{array}$ & Frequency & $(\%)$ & Cumulative (\%) \\
\hline $501-1000$ & 1 & 50 & 50 \\
$1501-2000$ & 1 & 50 & 100 \\
\hline Total & 2 & 100 & \\
\hline
\end{tabular}

Table 6

Complications-1st twin

\begin{tabular}{lccc}
\hline Complication & Frequency & $(\%)$ & Cumulative (\%) \\
\hline Asphyxia & 73 & 42.9 & 42.9 \\
Prematurity & 50 & 29.4 & 72.3 \\
Asphyxia/ & & & \\
Prematurity & 19 & 11.2 & 83.5 \\
$\quad$ BBA & 1 & 0.6 & 84.1 \\
FSB & 8 & 4.7 & 88.8 \\
MSB & 14 & 8.2 & 97 \\
$\quad$ RDS & 4 & 2.4 & 99.4 \\
Retained twin & 1 & 0.6 & 100 \\
\hline Total & 170 & & \\
\hline
\end{tabular}

$\mathrm{BBA}=$ Birth before arrival

$\mathrm{FSB}=$ Fresh stillbirth

$\mathrm{MSB}=$ Macerated stillbirth

RDS=Respiratory distress syndrome
Table 7

Complications- 2nd twin

\begin{tabular}{lccc}
\hline & Frequency & $(\%)$ & Cumulative $(\%)$ \\
\hline Asphyxia & 62 & 41.3 & 41.3 \\
Prematurity & 57 & 38 & 79.3 \\
Asphyxia/ & & & \\
Prematurity & 18 & 12 & 91.3 \\
$\quad$ FSB & 7 & 4.7 & 96 \\
MSB & 6 & 4 & 100 \\
\hline Total & 150 & & \\
\hline
\end{tabular}

Tables 3, 4 and 5 show the weight distribution of the various orders of twins. Most of the twins were in the low birth weight category that is, below $2500 \mathrm{gms}$ $67.5 \%$ in the first twin and $12.6 \%$ in the second twin. The mean weight in first twin was $2221.0 \mathrm{gms}$, second twin 2188 gms and 1450 gms in the triplets.

Tables 6 and 7 show the different neonatal complications of both first and second twins. The most common complications in both orders of twins are prematurity and asphyxia. Most of the neonates however had no complications

Table 8

Maternal complications

\begin{tabular}{lccc}
\hline Complication & Frequency & $(\%)$ & Cumulative $(\%)$ \\
\hline Anaemia & 12 & 13.0 & 13.0 \\
APH & 1 & 1.1 & 14.1 \\
Cord prolapse & 1 & 1.1 & 15.2 \\
Foetal distress & 1 & $1 . \mathrm{I}$ & 16.3 \\
PET & 65 & 70.7 & 87.0 \\
Polyhydramnios & 1 & 1.1 & 88.1 \\
Preterm labour & 4 & 4.3 & 92.4 \\
PROM & 5 & 5.4 & 97.8 \\
PROM/PET & 2 & 2.1 & 100 \\
\hline
\end{tabular}

\begin{tabular}{lll}
\hline Total & 92 & 100 \\
\hline
\end{tabular}

$\mathrm{APH}=$ Ante partum haemorrhage

PET=Pre-eclampsia

PROM=Premature rupture haemorrhage

The most common maternal complications were PET and anaemia though the majority of the mothers had no complications.

\section{DISCUSSION}

This study shows that the majority of the women with multiple pregnancies were in the lower age group. Most of them were of low parity. Studies done show that dizygotic twins are affected by maternal age, race, heredity, parity and fertility drugs $(3,4)$ than monozygotic twins that is increases from 3 in 1000 women less than 20 years to 4 per 1000 in women $35-40$ years $(7,8)$. In our study the frequency of twin pregnancy did not increase with advancing age. 
The frequency of twins in our study is one in 48 deliveries and one in 7821 deliveries for triplets. This is comparable to other studies one in 58 and one in $46(5,6)$. Twinning is also affected by parity $(9,10)$. Our study does not show any increase with increasing parity. Naturally occurring triplet births occur approximately in one per 7000-10000 births. Naturally occurring quadruplets births occur in one per 600,000 deliveries.

The foetal mortality rate for twins is four times the mortality rate for singleton births. The neonatal mortality rate for twins is six times more than singletons and increases with higher order pregnancies (11-13). In our study the majority of the babies were live births.

In this study the most common neonatal complications were prematurity and asphyxia. The most common complications were due to associated low birth weight due to prematurity and intrauterine growth retardation and their associated complications (14).Second twinshad morecomplications as compared to first twins. This is in keeping with other studies (15). Historically second twins were reported to have a higher incidence of adverse outcomes e.g. reduced birth weights, increased incidence of malpresentations, prolonged interval of more than minutes between delivery of the first and the second twin was thought to be associated with poorer outcomes.

Twins have twice the frequency of congenital malformations. In our study we only had two cases of congenital malformations involving the skeletal and the central nervous system. The frequency is too small for proper evaluation.

In our study most of the diagnosis was done in the antenatal period. This is in keeping with other studies and this is due to detection of signs like: excessive weight gain, hyperemesis gravidarum or sensation of more than one foetus moving. Early diagnosishelpsin the management after maternal and induced risk factors are taken into account. Maternal ultrasonography is normally the confirmatory investigation. In our study the majority of the prenatal diagnosis was madeby ultrasonography and most of the deliveries were by spontaneous vertex delivery. The most common maternal complications were PET and anaemia. This is in keeping with many studies. Anaemia could be due to increased demands.

In conclusion, this was a preliminary study to look at some aspects of multifoetal pregnancies as seen at PMH. From this study we recommend that health care workers still need to have clinical acumen to diagnose multiple pregnancies especially in situations where ultrasonography is not available; we need to look at other predisposing factors in the causation of multiple pregnancies and to do a more comprehensive study on the types of placentation as this will enable us to know the type of twins. The babies will need a longer follow up so as to determine whether there are long term effects of multiple pregnancies. For comparison we need to do a study to get the statistics for the year 2007.

\section{ACKNOWLEDGEMENTS}

We thank Dr. C. Wanyonyi, The Medical Superintendent Pumwani Maternity Hospital, for granting us consent to undertake the study and the encouragement during the study period and to Ms. Margaret Manyonje for data collection.

\section{REFERENCES}

1. Beischer, N.A. and Mackay, E. V.Multiple pregnancy: In: Obstetrics and the newborn: An Illustrated Textbook: 3rd Ed. London, England. Bailliere Tindall 1997; 258-273.

2. Bernrsche, K. and Kim, C.K. Multiple pregnancy 1: N. Engl. J. Med. 1973; 288: 1276-1284.

3. Salihu, H.M. Racial disparity in stillbirth among singletons, twins and triplet gestations in the United States. Obs. Gynae. 2004; 104: 734-740.

4. Benson, R. C. and Pernol, M. L. Multiple pregnancy In: Current obstetric and gynaecology diagnosis and treatment $7^{\text {th }}$ Edition Appleton and Lange. 1991.

5. Oyieke, J.B.O. A 2 year review of some aspects of twin delivery in Kenyatta National Hospital. MMed Thesis. University of Nairobi, 1978.

6. Mutungi, A. K. A prospective study of twin delivery at Kenyatta National Hospital- The antenatal care and delivery. M.Med Thesis. University of Nairobi. 1990.

7. Smith, L. M. Multifetal pregnancies: Epidemiology, clinical characteristics and management: Reece E.A, Hobbins J.C Eds. Medicine of the foetus and mother. Lippincot-Raven 1999; 243-265.

8. Spellacy, W.M. Multiple pregnancies In: Smith J.R Danfords Obstetrics and Gynaecology. Philadelphia P.A Lippincot. Raven. 1999; 293-300.

9. Garitte, T.J. and Clark, R. H. Twins and triplets: The effect of plurality and growth on neonatal outcome compared with singletoninfants. Am. Obstet. Gynaecol. 2004; 191: 700-707.

10. Henderson, J. and Hockley, C. Economicimplications of multiple births: Inpatient hospital costs in the first 5 years of life. Arch. Dis. Child. Fetal Neonatal Ed. 2004; 89: $542-545$.

11. Lambalk, C.B. Maternal versus induced twinning and pregnancy outcome: A Dutch nationwide survey of primiparous dizygotic deliveries. Fertil. Steril. 2001; 75: 731-736.

12. Malone, F.D. Anomalies peculiar to multiple gestations. Clin. Perinatol. 2000; 27: 1033-1046.

13. McCulloch, K. Neonatal profiles in twins. Clin. Perinatol. 1988; 15: 141-158.

14. Nielsen, H.C. Neonatal outcome of very premature infants from multiple and singleton gestations. Am. J. Obstet. Gynaecol. 1997; 177: 653-659.

15. Hibbard, B. M. Multiple pregnancy. In: Principes of obstetrics. $1^{\text {st }}$ Edition. Butterworth \& Co. 1988. 